\title{
Comparison of Debrisoquine and Guanethidine in Treatment of Hypertension
}

\author{
F. C. ADI, C. J. EZE, A. ANWUNAH
}

British Medical fournal, 1975, 1, 482-485

\begin{abstract}
Summary
A cross-over trial of debrisoquine and guanethidine in 32 patients showed that both drugs were equally effective in lowering both systolic and diastolic blood pressure. The degree to which they were tolerated by the patients, however, differed greatly. After three months on each drug 18 patients preferred debrisoquine, nine preferred guanethidine, and five showed no particular preference. At current prices the cost of daily treatment to the patient was cheaper with debrisoquine than with guanethidine.
\end{abstract}

\section{Introduction}

Published work shows that both guanethidine and debrisoquine are potent hypotensive agents in the management of moderate to severe cases of hypertension. Though both drugs act on the postganglionic sympathetic nerves, interfering with the release of noradrenaline at their nerve endings, their side effects though similar are not equally severe. Heffernan and Carty (1970) in their initial studies with debrisoquine were impressed with the low incidence of side effects. Though bethanidine, guanethidine, and methyldopa (Prichard et al., 1968) and debrisoquine and methyldopa (Heffernan et al., 1971) have been compared there has been no formal comparative clinical trial between debrisoquine and guanethidine. We therefore made a within-patient comparison of the effectiveness and tolerability of debrisoquine and guanethidine using the principles (with slight modifications) established by Prichard et al. (1968).

\section{Patients and Methods}

Patients were selected to take part in the trial if $(a)$ they had moderate to severe hypertension with a standing diastolic blood pressure of $110 \mathrm{~mm} \mathrm{Hg}$ or above; (b) they were not ill enough to warrant admission to hospital for either the hypertension or its renal, cardiac, or cerebrovascular complications and so could be safely managed as outpatients; $(c)$ they had had no regular antihypertensive treatment for the past four weeks; and $(d)$ they agreed to attend every two weeks in return for receiving their drugs free of charge.

We explained to the patients that two drugs known to be equally effective in treating hypertension were going to be given to them free of charge for three to four months at a time and that we wanted to know which of the two drugs they preferred and their reasons for such preference.

\section{INITIAL ASSESSMENT}

The 85 patients so selected were questioned, using a specially prepared questionnaire form, on all essential details including a

University of Nigeria Teaching Hospital, Enugu, Nigeria

F. C. ADI, M.R.C.P., F.M.C.P., Consultant Physician

C. J. EZE, M.B., B.S., Senior House Office

A. C. ANWUNAH, M.D., Registrar. close estimate of age and the presence or absence of symptoms such as dizziness, weakness, and state of the libido. From the start a level of standing diastolic pressure was chosen for each patient (based on the age) which would be regarded as indicating a satisfactory degree of control of his blood pressure. For those under the age of 40 a standing diastolic blood pressure of $90 \mathrm{~mm}$ $\mathrm{Hg}$ or below indicated good control while for those over a standing diastolic pressure of $100 \mathrm{~mm} \mathrm{Hg}$ or less indicated good control. Levels not more than $10 \mathrm{~mm} \mathrm{Hg}$ above the chosen diastolic pressures were regarded as showing fair control, but inability to achieve even a fair control or the occurrence of intolerable side effects necessitating stoppage of the drug was regarded as failure of treatment.

Each patient had a "run-in" period lasting usually two to four weeks at the start of the trial on either guanethidine or debrisoquine, as randomly allotted. The aim was to adjust the dose of each drug to achieve good or fair control of the blood pressure before the proper period of assessment. Also during this run-in period the patient became familiar wth the clinic routine and various investigations were performed. All except four oc the 32 patients who completed the trial had a satisfactory run-in. The following period of assessment lasted three months for each drug, during which time the patients made seven fortnightly visits to the clinic.

\section{DRUGS AND DOSAGE}

The drugs were given as $25-\mathrm{mg}$ (pink) or 10-mg (white) tablets of quanethidine (Ismelin) and $20-\mathrm{mg}$ (light blue) or 10-mg (white) tablets of debrisoquine (Declinax). Both drugs were given in a twice- or occasionally thrice-daily dose regimen. The varying strengths and colours of the tablets helped to prevent the patients from knowing which drug they were being given during each visit to the clinic.

\section{CLINIC ROUTINE}

After questioning the patients about specific symptoms during the first visit and run-in period they were not specifically asked about any symptoms during the trial but merely questioned about how they felt, and any symptoms they complained of spontaneously were duly recorded. Blood pressure was measured by A.A. or C.E. using a mercury sphygmonanometer after the patient had been resting in the supine position for about three minutes and after standing free of all support for one minute. In each position three readings were taken and the lowest diastolic pressure reading taken as the true reading. These observers were "blind" as regards the previous blood pressure readings, the drugs being taken, and the symptoms (if any) complained of by the patient. One of us (F.C.A.) supervized the clinical trial and knew everything about the patient but did not take blood pressure. He saw the patient after the blood pressure had been taken, recorded the pressure as well as the patients' symptoms, made any necessary adjustments in the drug dose, and personally dispensed the drugs.

During each visit to the clinic the patients were weighed. Polythiazide (Renese) $2 \mathrm{mg}$ daily or $4 \mathrm{mg}$ on alternate days was added to the treatment regimen if the weight rose by more than $1 \mathrm{~kg}$ or the patient showed any pitting leg oedema or complained of shortness of breath on exertion.

At the end of the first three months the patient was specifically questioned about symptoms whiah had been prelisted in the original questionnaire, and any new ones were noted. He was then quickly run-in using the second drug and another three-month period of assessment followed on that drug. At the end of the trial the patient was asked which of the two drugs he preferred and the reasons for his preference. 


\section{Results}

\section{WITHDRAWALS FROM THE TRIAL}

Altogether 53 patients were withdrawn from the trial at various stages. One person was withdrawn while receiving guanethidine during the second assessment period because of severe diminution in libido and failure of ejaculation. Twenty-seven people were withdrawn while receiving guanethidine and 25 while receiving debrisoquine because of their irregular attendance at the clinic at various stages of the trial. Apart from those who permanently defaulted from the clinic, usually within the first three months, the rest gave various reasons unrelated to side effects for their irregular attendance. Some failed to keep an appointment because of the death of a relative or because they could not afford the transport fare to come to the hospital every two weeks or because they felt so well that they thought they had been cured permanently.

A total of 32 patients- 21 men and 11 women-satisfied the rigid protocol required of the trial and their details are shown in table $\mathrm{I}$.

\section{BLOOD PRESSURE CONTROL}

Altogether 29 of the 32 patients while on guanethidine and 28 while on debrisoquine attained good control of their blood pressure and three on each drug attained fair control (table I). One patient (case 30) though classified as having poor control while on debrisoquine nevertheless benefited considerably from the therapy since his diastolic blood pressure fell from $160 \mathrm{~mm}$ $\mathrm{Hg}$ before the trial to a mean value of $110 \mathrm{~mm} \mathrm{Hg}$ while on debrisoquine.

Both drugs produced a good control of systolic and diastolic blood pressures, which in fact was our objective. Statistically, however, there was no difference between the mean systolic and diastolic standing blood pressures for these 32 patients on guanethidine and on debrisoquine. The mean ( \pm S.D.) systolic standing blood pressure before the trial was 188.33 \pm 20.07 $\mathrm{mm} \mathrm{Hg}$ while the mean after guanethidine was $133.5 \pm 18.94$ $\mathrm{mm} \mathrm{Hg}$ and after debrisoquine $134.5 \pm 18.83 \mathrm{~mm} \mathrm{Hg}$. Similarly, the mean baseline standing diastolic blood pressure was $123.6 \pm 11.31 \mathrm{~mm} \mathrm{Hg}$, and this fell to $88.49 \pm 11.38 \mathrm{~mm} \mathrm{Hg}$ after guanethidine and $92.65 \pm 10.98 \mathrm{~mm} \mathrm{Hg}$ after debrisoquine.

TABLE I-Details of Patients and Average Blood Pressures from Periods of Assessment

\begin{tabular}{|c|c|c|c|c|c|c|c|c|c|c|c|c|c|c|}
\hline \multirow{3}{*}{$\begin{array}{l}\text { Case } \\
\text { No. }\end{array}$} & \multirow{3}{*}{$\begin{array}{c}\text { Sex } \\
\text { and } \\
\text { Age } \\
\text { Range }\end{array}$} & \multirow{3}{*}{$\begin{array}{c}\text { Type } \\
\text { of } \\
\text { Hyper- } \\
\text { tension }\end{array}$} & \multirow{3}{*}{$\begin{array}{c}\text { Pretreatment } \\
\text { Standing } \\
\text { Blood Pressure } \\
(\mathrm{mm} \mathrm{Hg})\end{array}$} & \multicolumn{3}{|c|}{ Run-in Period } & \multicolumn{4}{|c|}{ Guanethidine Treatment } & \multicolumn{3}{|c|}{ Debrisoquine Treatment } & \multirow{3}{*}{$\begin{array}{c}\text { Poly- } \\
\text { thiazide }\end{array}$} \\
\hline & & & & \multirow[t]{2}{*}{$\begin{array}{c}\text { Fundus } \\
\text { Grade }\end{array}$} & \multirow[t]{2}{*}{$\underset{\text { Urea }}{\text { Blood }}$} & \multirow[t]{2}{*}{$\begin{array}{l}\text { Standing } \\
\text { Blood Pressure } \\
(\mathrm{mm} \mathrm{Hg})\end{array}$} & \multicolumn{2}{|c|}{$\begin{array}{c}\text { Mean } \\
\text { Blood Pressure } \\
(\mathrm{mm} \text { Hg) }\end{array}$} & \multirow[t]{2}{*}{$\underset{\text { (mg/day) }}{\text { Dose }}$} & \multirow[t]{2}{*}{$\begin{array}{l}\text { Poly- } \\
\text { thiazide }\end{array}$} & \multicolumn{2}{|c|}{$\begin{array}{c}\text { Mean } \\
\text { Blood Pressure } \\
(\mathrm{mm} \mathrm{Hg})\end{array}$} & \multirow[t]{2}{*}{$\underset{(\mathrm{mg} / \text { day })}{\text { Dose }}+$} & \\
\hline & & & & & & & Supine & Standing & & & Supine & Standing & & \\
\hline 1 & $\begin{array}{c}M \\
40-49 \\
M\end{array}$ & R. & $165 / 120$ & 2 & 4.930 & $165 / 120^{*}$ & $130 / 100$ & $130 / 100$ & $75(1)$ & + & $120 / 80$ & $110 / 80$ & 60 & + \\
\hline 2 & $\begin{array}{c}50-59 \\
\text { F. }\end{array}$ & E. & $180 / 110$ & 0 & 5.533 & $170 / 95$ & $160 / 80$ & $116 / 68$ & $50(1)$ & + & $150 / 80$ & $120 / 80$ & 50 & - \\
\hline 3 & $\begin{array}{c}30-39 \\
\mathrm{~F} .\end{array}$ & $\mathbf{R}$. & $180 / 120$ & 2 & 3.924 & $160 / 110$ & $164 / 100$ & $116 / 80$ & $37 \cdot 5$ & + & $160 / 90$ & $130 / 90$ & $60(1)$ & + \\
\hline 4 & $\begin{array}{c}40-49 \\
\text { M. }\end{array}$ & R. & $190 / 120$ & 2 & $7 \cdot 143$ & $130 / 90$ & $160 / 100$ & $140 / 80$ & $30(1)$ & + & $145 / 100$ & $120 / 100$ & 40 & + \\
\hline 5 & $\begin{array}{c}50-59 \\
\text { M. }\end{array}$ & E. & $220 / 140$ & 2 & $2 \cdot 5 \quad 15$ & $180 / 90$ & $220 / 110$ & $160 / 90$ & $37 \cdot 5$ & - & $190 / 100$ & $180 / 90$ & $60(1)$ & + \\
\hline 6 & $\begin{array}{c}40-49 \\
\mathrm{M} .\end{array}$ & E. & $180 / 120$ & 2 & $3 \cdot 2 \quad 19$ & $180 / 120^{*}$ & $140 / 100$ & $130 / 100$ & $50(1)$ & + & $134 / 90$ & $128 / 88$ & 60 & + \\
\hline 7 & $\begin{array}{c}40-49 \\
M\end{array}$ & E. & $176 / 118$ & 1 & $7 \cdot 344$ & $140 / 90$ & $170 / 90$ & $140 / 100$ & 30 & + & $170 / 90$ & $130 / 90$ & $30(1)$ & - \\
\hline 8 & $\begin{array}{c}40-49 \\
\text { F. }\end{array}$ & E. & $170 / 125$ & 2 & 3.722 & $190 / 110$ & $140 / 80$ & $140 / 90$ & $40(1)$ & + & $140 / 80$ & $140 / 85$ & 60 & + \\
\hline 9 & $\begin{array}{c}40-49 \\
F .\end{array}$ & R. & $210 / 110$ & 2 & $4 \cdot 2 \quad 25$ & $190 / 118$ & $170 / 100$ & $130 / 88$ & $25(1)$ & + & $180 / 100$ & $150 / 90$ & 60 & - \\
\hline 10 & $\begin{array}{c}30-39 \\
\text { M. }\end{array}$ & R. & $190 / 125$ & 2 & 5.533 & $168 / 115$ & $130 / 80$ & $95 / 70$ & $50(1)$ & + & $120 / 90$ & $100 / 80$ & 40 & + \\
\hline 11 & $\begin{array}{c}40-49 \\
\text { M. }\end{array}$ & E. & $170 / 120$ & 2 & $5 \cdot 8 \quad 35$ & $170 / 100$ & $170 / 90$ & $130 / 90$ & 37.5 & + & $160 / 100$ & $150 / 100$ & $50(1)$ & + \\
\hline 12 & $\begin{array}{c}50-59 \\
\mathrm{~F} .\end{array}$ & E. & $200 / 120$ & 2 & 4.930 & $130 / 100$ & $180 / 100$ & $110 / 70$ & $50(1)$ & - & $150 / 90$ & $120 / 90$ & 40 & + \\
\hline 13 & $\begin{array}{c}30-39 \\
\text { M. }\end{array}$ & R. & $190 / 120$ & 2 & 5.936 & $160 / 110$ & $160 / 90$ & $150 / 90$ & $37 \cdot 5$ & + & $130 / 70$ & $140 / 80$ & $40(1)$ & - \\
\hline 14 & $\begin{array}{l}40-49 \\
M\end{array}$ & R. & $180 / 120$ & 2 & 6.137 & $160 / 106$ & $165 / 100$ & $150 / 100$ & $50(1)$ & - & $160 / 90$ & $130 / 98$ & 60 & - \\
\hline 15 & $\begin{array}{l}40-49 \\
\mathrm{M} .\end{array}$ & E. & $190 / 130$ & 2 & $4 \cdot 2 \quad 25$ & $170 / 120$ & $160 / 100$ & $140 / 100$ & $50(1)$ & + & $160 / 110$ & $130 / 100$ & 60 & + \\
\hline 16 & $\begin{array}{c}40-49 \\
\mathrm{M}\end{array}$ & E. & $200 / 130$ & 2 & 5.936 & $170 / 120$ & $140 / 80$ & $150 / 100$ & 37.5 & + & $170 / 100$ & $150 / 100$ & $50(1)$ & + \\
\hline 17 & $\begin{array}{c}40-49 \\
M\end{array}$ & R. & $170 / 120$ & 2 & 3.521 & $170 / 120^{*}$ & $186 / 106$ & $150 / 96$ & $50(1)$ & + & $150 / 100$ & $140 / 110$ & 60 & + \\
\hline 18 & $\begin{array}{c}40-49 \\
\mathrm{M} .\end{array}$ & R. & $190 / 130$ & 2 & $10 \cdot 6(64)$ & $160 / 110$ & $130 / 90$ & $100 / 65$ & $100(1)$ & + & $150 / 110$ & $150 / 90$ & 50 & + \\
\hline 19 & $\begin{array}{c}50-59 \\
\text { F. }\end{array}$ & E. & $210 / 110$ & 2 & 5.533 & $210 / 110$ & $180 / 90$ & $170 / 90$ & 20 & - & $150 / 85$ & $140 / 90$ & $30(1)$ & - \\
\hline 20 & $\begin{array}{c}30-39 \\
\mathrm{~F} .\end{array}$ & R. & $210 / 125$ & 2 & $5 \cdot 6 \quad 34$ & $140 / 110$ & $165 / 110$ & $150 / 100$ & 37.5 & + & $170 / 115$ & $140 / 80$ & $50(1)$ & - \\
\hline 21 & $\begin{array}{c}40-49 \\
\mathrm{M} .\end{array}$ & E. & $170 / 150$ & 2 & $3 \cdot 320$ & $200 ; 120$ & $145 / 115$ & $146 / 105$ & $50(1)$ & - & $200 / 120$ & $150 / 100$ & 80 & - \\
\hline 22 & $\begin{array}{c}30-39 \\
\mathrm{~F} .\end{array}$ & E. & $140 / 110$ & 0 & $7 \cdot 5 \quad 45$ & $130 / 110$ & $130 / 90$ & $110 / 90$ & 10 & - & $110 / 90$ & $110 / 90$ & $20(1)$ & - \\
\hline 23 & $\begin{array}{c}30-39 \\
\mathrm{~F} .\end{array}$ & R. & $230 / 140$ & 2 & $5 \cdot 6 \quad 34$ & $180 / 120^{*}$ & $130 / 80$ & $120 / 85$ & $62 \cdot 5$ & - & $140 / 95$ & $120 / 90$ & $80(1)$ & + \\
\hline 24 & $\begin{array}{c}30-39 \\
\mathrm{M}\end{array}$ & R. & $180 / 130$ & 2 & $8 \cdot 350$ & $180 / 110$ & $170 / 108$ & $150 / 98$ & $50(1)$ & + & $160 / 90$ & $150 / 100$ & 60 & - \\
\hline 25 & $\begin{array}{c}40-49 \\
\mathrm{M} .\end{array}$ & E. & $190 / 120$ & 2 & $4.5 \quad 27$ & $150 / 100$ & $130 / 90$ & $120 / 90$ & 50 & + & $130 / 90$ & $120 / 90$ & $60(1)$ & + \\
\hline 26 & $\begin{array}{c}50-59 \\
\mathrm{M}\end{array}$ & R. & $180 / 120$ & 2 & $9 \cdot 5 \quad 57$ & $170 / 105$ & $190 / 110$ & $130 / 80$ & $40(1)$ & + & $170 / 100$ & $130 / 90$ & 60 & + \\
\hline 27 & $\begin{array}{c}50-59 \\
\mathrm{M} .\end{array}$ & E. & $185 / 115$ & 1 & $\begin{array}{ll}4 \cdot 5 \quad 27 \\
\end{array}$ & $150 / 100$ & $150 / 90$ & $150 / 90$ & 40 & + & $140 / 90$ & $140 / 90$ & $60(1)$ & + \\
\hline 28 & $\begin{array}{c}50-59 \\
\mathrm{M} .\end{array}$ & E. & $180 / 110$ & 1 & $2 \cdot 8 \quad 17$ & $174 / 108$ & $160 / 90$ & $120 / 90$ & $40(1)$ & + & $140 / 80$ & $110 / 64$ & 60 & - \\
\hline 29 & $\begin{array}{c}50-59 \\
F .\end{array}$ & E. & $170 / 130$ & 2 & $4.5 \quad 27$ & $140 / 90$ & $140 / 90$ & $110 / 90$ & 50 & + & $120 / 100$ & $120 / 100$ & $40(1)$ & + \\
\hline 30 & 30-39 & R. & $240 / 160$ & 2 & 5.533 & $180 / 110$ & $200 / 120$ & $100 / 80$ & $50(1)$ & + & $150 / 110$ & $150 / 110$ & 60 & - \\
\hline 31 & $\begin{array}{c}40-49 \\
\text { F. }\end{array}$ & E. & $200 / 120$ & 2 & $2 \cdot 7 \quad 16$ & $140 / 100$ & $140 / 100$ & $130 / 85$ & 50 & + & $130 / 85$ & $120 / 85$ & $60(1)$ & - \\
\hline 32 & $40-49$ & R. & $190 / 120$ & 2 & $9 \cdot 8 \quad 59$ & $160 / 100$ & $160 / 105$ & $150 / 90$ & $90(1)$ & - & $180 / 110$ & $170 / 110$ & 60 & - \\
\hline
\end{tabular}

* Incompletely run-in cases.

+ (1) Indicates that the drug under which heading symbol appears was given first.

R. = Renal. E. = Essential.

Conversion: SI to Traditional Units-Urea: $1 \mathrm{mmol} / 1 \simeq 6 \mathrm{mg} / 100 \mathrm{ml}$. 


\section{DRUG DOSAGE}

The mean daily dose for the whole group was $46 \cdot 2 \pm 17 \cdot 66$ $\mathrm{mg} /$ day of guanethidine and $53.6 \pm 13.11 \mathrm{mg} /$ day of debrisoquine (table I). In addition, 19 patients while on debrisoquine and 24 patients while on guanethidine received polythiazide 2 $\mathrm{mg}$ daily or $4 \mathrm{mg}$ on alternate days for short periods to control a tendency to fluid retention.

\section{SIDE EFFECTS}

The symptoms which were specifically asked about before the trial and again at the end of each period of assessment are shown in table II. Occasional headache did not correlate with level of

TABLE II-Side Effects Before Trial and on Both Drugs

\begin{tabular}{|c|c|c|c|c|}
\hline & & \multicolumn{3}{|c|}{ No. of Patients showing Listed Symptoms } \\
\hline & & Before Trial & On Guanethidine & On Debrisoquine \\
\hline 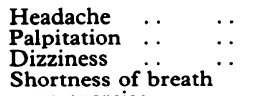 & $\begin{array}{l}. \\
\cdots\end{array}$ & $\begin{array}{l}19 \\
14 \\
13\end{array}$ & $\begin{array}{r}13 \\
1 \\
7\end{array}$ & $\begin{array}{r}13 \\
3 \\
6\end{array}$ \\
\hline $\begin{array}{ll}\text { on exercise } & \ldots \\
\text { Weakness } & \ldots \\
\text { Blurred vision } & \ldots \\
\text { Cough } & \ldots \\
\text { Diminished libido } & \ldots \\
\text { Delayed ejaculation. . } \\
\text { Nasal stuffiness } \\
\text { Mild postural dizziness } \\
\text { Severe postural dizziness } \\
\text { Diarrhoea .. }\end{array}$ & $\begin{array}{l}\cdots \\
\cdots \\
\cdots \\
\cdots \\
\cdots \\
\cdots \\
\cdots\end{array}$ & $\begin{array}{r}11 \\
11 \\
7 \\
3 \\
2\end{array}$ & $\begin{array}{r}6 \\
16 \\
2 \\
6 \\
6 \\
7 \\
11 \\
10 \\
4 \\
2\end{array}$ & $\begin{array}{l}1 \\
6 \\
1 \\
5 \\
5 \\
4 \\
4 \\
3 \\
4 \\
1 \\
1\end{array}$ \\
\hline
\end{tabular}

blood pressure though the few patients who had genuine nocturnal or early morning headache lost these after treatment with either drug. The major side effects which patients found most troublesome were delayed ejaculation and diminished libido. No women admitted to having any sexual difficulty. Many of the men were shy in spontaneously mentioning their sexual difficulties and even on direct questioning admitted to some difficulty only in private-that is, with no female nurse or interpreter present. Fewer patients had sexual difficulties on debrisoquine than on guanethidine, but the difference was not statistically significant. Nevertheless, guanethidine did seem to produce more postural dizziness and nasal stuffiness than debrisoquine.

\section{DRUG PREFERENCE}

At the end of the trial patients were asked which of the two drugs they preferred. Eighteen patients preferred debrisoquine, nine preferred guanethidine, and five said both drugs were equally good. Ignoring those who showed no particular preference the preference of most of the patients for debrisoquine over guanethidine was statistically significant $(P<0.05)$. The reasons for such preference were mainly that debrisoquine caused less postural dizziness, less weakness and shortness of breath and, in the men, fewer instances of delayed ejaculation and diminished libido. Some patients required nasal drops while on guanethidine to relieve nasal stuffiness, particularly at night, but they did not seem to have associated this symptom with the drug until told at the end of the trial.

EFFECT OF ORDER OF DRUG ADMINISTRATION ON PATIENTS' PREFERENCE

The effect of the order of administration of drugs on the patients' stated preference at the end of the trial is shown in table III. Though about the same number of patients were started on each drug in a randomized manner at the beginning of the trial of those who completed the trial 18 received debrisoquine last and 14 received guanethidine last. Hence there was a pronounced tendency for the patients to prefer the drug last administered-a finding similar to that of Prichard et al. (1968).

TABLE III-Effect of Order of Administration of Drugs on Patients' Preference

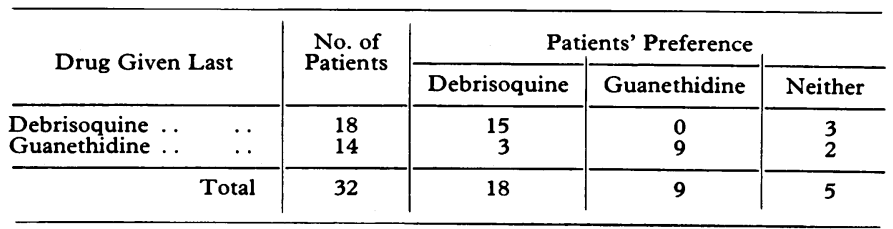

\section{COST OF DRUGS}

Excluding the cost of polythiazide used in the trial the cost to the patient, had he paid for the drugs at retail prices, ranged from $\$ 1.50^{*}$ to $\$ 13.20$ a month when guanethidine (Ismelin) was used. When debrisoquine (Declinax) was used, however, the cost ranged from $\$ 1.50$ to $\$ .00$ a month. For the group as a whole it cost about $\$ 6.60$ a day to use guanethidine in the treatment of hypertension compared with 3.90 a day using debrisoquine, and the average cost per patient per day was 0.20 on guanethidine and $\$ 0.12$ on debrisoquine. When the cost of polythiazide (Renese), which is one of the cheapest diurectics, is added ( $\$ 0.05$ a tablet) the cost for the whole group of treatment with guanethidine increased still further compared with that of treatment with debrisoquine.

We purposely used proprietary drugs in assessing the cost of treatment as prices of unbranded drugs vary. Though unbranded drugs tend to be cheaper, in many developing countries where there is no drug quality control ordinary starch or chalk tablets have been sold under all kinds of generic names.

\section{Discussion}

Guanethidine and debrisoquine were equally effective in lowering the blood pressure in cases of moderate to severe hypertension and in only one person were side effects sufficiently severe to warrant discontinuation of the drug during the trial period. The side effects of the two drugs were similar, as would be expected from their known pharmacological action of adrenergic neurone blockade, but they varied in degree. Guanethidine tended to cause more postural dizziness, nasal stuffiness, weakness, and fluid retention than debrisoquine. More patients, therefore, preferred debrisoquine though such a preference must have been partially due to the well-known tendency for patients undergoing this sort of trial to prefer the drug last administered, probably because they become more tolerant of the side effects as the trial proceeds. On the other hand, this factor could not have accounted wholly for the patients' preference for debrisoquine because any really serious side effect of the drug last administered would have been fresh in the mind of the patient at the end of the trial and would have tended to adversely influence his choice of this drug.

There may well be some subtle differences in the action of both drugs in the body which gives debrisoquine a slight edge over guanethidine as far as the patients' subjective assessment is concerned. Obviously more work is needed to test these differences on a larger group of patients and to carry out a more detailed statistical analysis of the results. Both drugs, however, have some serious side effects in men-namely, diminution of libido and delayed or scanty ejaculation, which patients may find very distressing. Though they may feel shy to complain about this to the doctor, especially in the presence of a woman, such side effects are likely to affect adversely the use of these drugs in the long-term management of hypertension in patients who suffer such side effects.

$* 100=£ 066 \mathrm{p}$ (\$U.S. 152) at time of writing. 
Debrisoquine's greatest advantage over guanethidine is it's cost. It costs the hypertensive patient about twice as much to be treated with guanethidine as it does to be treated with debrisoquine. For most people in the developing countries, where average incomes are low, and for all people who have to pay for their own drugs this fact is important and should be borne in mind by doctors if life-long treatment of patients' hypertension is to be achieved.

We thank Dr. J. N. Adichie, head of the department of statistics,
University of Nigeria, Nsukka, for help with the statistical analysis. We are also grateful to Roche Ltd. for supplying Declinax, Ciba Ltd. for supplying Ismelin, and Pfizer Products Ltd. for supplying Renese.

\section{References}

Heffernan, A. G. A., and Carty, A. T. (1970). Irish fournal of Medical Sciences, 3, 37

Heffernan, A., et al. (1971). British Medical fournal 1, 75-8.

Prichard, B. N. C., et al. (1968). British Medical fournal, 1, 135.

\title{
Pulmonary Function in Asthmatic Patients in Remission
}

\author{
K. N. V. PALMER, G. R. KELMAN
}

British Medical fournal, 1975, 1, 485-486

\section{Summary}

Thirty-five asthmatic patients (average age 28 years) who attended a pulmonary function laboratory when their mean ratio of forced expiratory volume in one second: forced vital capacity was $81 \%$ (within the normal range for their age group) had arterial hypoxaemia and hypocapnia. These were probably secondary to lung hyperinflation and pulmonary ventilation/perfusion imbalance. The pulmonary abnormalities of bronchial asthma are not always detected by simple spirometric tests and the results of such tests should be interpreted cautiously.

\section{Introduction}

The variety and sophistication of pulmonary function tests are ever increasing, but to many doctors, particularly in general practice, "pulmonary function testing" is confined to the use of a recording spirometer, such as a Vitalograph. There are still many clinicians who, despite evidence to the contrary (Levine et al., 1970; Cade and Pain, 1973), will accept a ratio of forced expiratory volume in one second: forced vital capacity $\left(\mathrm{FEV}_{1}\right.$ : FVC) above $70 \%$ as excluding significant airways obstruction and other pulmonary dysfunction in bronchial asthma. We present here further evidence that they are wrong to do so; some patients may have significant pulmonary hyperinflation and arterial hypoxaemia with hypocapnia.

\section{Patients and Methods}

The 35 patients (13 men, 22 women) all had a clinical history of asthma with paroxysmal dyspnoea, wheezing, and blood or sputum eosinophilia or both. Their mean age $( \pm$ S.D.) was $28.3 \pm 13.8$ years. On skin-prick tests 28 reacted immediately to various allergens, mainly pollen and house-dust mite, and were considered to have extrinsic asthma. Drug treatment was discontinued for at least 12 hours before pulmonary function testing, except in one patient who was taking $5 \mathrm{mg}$ daily of prednisone by mouth and

Department of Medicine, University of Aberdeen, Aberdeen AB9 2ZD

K. N. V. PALMER, M.D., F.R.C.P., Reader in Medicine

Department of Physiology, University of Aberdeen, Aberdeen AB9 2ZD

G. R. KELMAN, M.D., M.R.C.P., Professor of Human Physiology

using an aerosol topical steroid (beclomethasone dipropionate) and one who was using the aerosol alone.

The following indicators of pulmonary function were measured: dynamic lung volumes: $\mathrm{FEV}_{1}$, FVC, the ratio $\mathrm{FEV}_{1}: \mathrm{FVC}_{\text {; static }}$ lung volumes: total lung capacity (TLC), functional residual capacity (FRC), residual volume (RV), the ratio RV:TLC; single breath carbon monoxide pulmonary diffusing capacity (DLCO); and arterial blood gases-Pao:, Paco,', and pH. The techniques used were as described previously (Palmer and Kelman, 1973).

\section{Results}

The mean values and percentage of predicted normal values are shown in table I. The mean $\mathrm{FEV}_{1}: \mathrm{FVC}$ ( \pm S.D.) was $81 \cdot 0$ $\pm 6.9 \%$, which was within the normal range for this age group (Higgins and Keller, 1973). Statistically significant differences $(\mathrm{P}<0.05)$ from the normal values predicted by Cotes (1968) were found in $\mathrm{FEV}_{1}, \mathrm{RV}$, and RV:TLC. $\mathrm{PaO}_{2}$ and $\mathrm{PaCO}_{2}$ also differed significantly $(P<0.001)$ from the normal values found by Diament and Palmer (1969) in non-asthmatic patients with an $\mathrm{FEV}_{1}: \mathrm{FVC}$ ratio greater than $70 \%$ (table II).

\section{Discussion}

Asthmatic patients in remission often continue to have abnormalities of both dynamic and static lung volumes (Levine et al., 1970; Teculescu and Stanescu, 1970; Mayfield et al., 1971; Cade and Pain, 1973). Our results show that even in patients with an $\mathrm{FEV}_{1}: \mathrm{FVC}$ greater than $70 \%$, who therefore fall within the normal range for patients in their age group (Higgins and Keller, 1973), there is still evidence of lung hyperinflation as shown by a statistically significant increase in RV:TLC to $113 \%$ and $\mathrm{RV}$ to $118 \%$ of their predicted normal values. The patients we examined also had arterial hypoxaemia and hypocapnia. Their blood gas tensions were significantly less $(P<0.001)$ than predicted values (Daiment and Palmer) (table II).

The fact that these patients had moderately reduced arterial, and therefore alveolar, carbon dioxide tensions meant that their alveolar oxygen tensions were correspondingly increased so that the observed low values of arterial $\mathrm{Po}_{2}$ were indicative of a greater increase in alveolar-arterial $\mathrm{Po}_{2}$ difference than would have been the case in the absence of hypocapnia. This suggests that these patients had appreciable degrees of ventilation/ perfusion imbalance.

The degree of arterial hypoxaemia we found in asymptomatic asthmatic patients was greater than that found by others. Valabhji (1968) found no evidence of arterial hypoxaemia (mean $\mathrm{PaO}_{2} 12.7 \mathrm{kPa}(95 \mathrm{~mm} \mathrm{Hg})$ ) in 12 asymptomatic asthmatic patients with a mean $\mathrm{FEV}_{1}: \mathrm{FVC}$ of $69.7 \%$, and Cade and Pain (1973) found that the mean $\mathrm{PaO}_{2}$ was only at the lower limit of 